\title{
HUBUNGAN ANTARA PARITAS DENGAN \\ KEJADIAN KEHAMILAN POSTTERM \\ DI RSUD EMBUNG FATIMAH \\ KOTA BATAM 2013
}

(Relationship between The Parity in The Event Postterm Pregnancy in The Embung Fatimah

Hospital Batam 2013)

Erika Fariningsih*

*) Dosen Prodi D-III Kebidanan STIKes Awal Bros Batam

\begin{abstract}
ABSTRAK
Penyebab mortalitas dan morbiditas salah satunya adalah kehamilan postterm. Karena sangat berpengaruh terhadap ibu dan janin yang dikandungnya. Pada janin dapat terjadi peningkatan berat badan secara terus menerus, ada yang tidak bertambah, ada yang lahir dengan berat badan kurang dari semestinya, atau meninggal dalam kandungan karena kekurangan zat makanan dan oksigen. Sementara itu, resiko bagi ibu dapat berupa perdarahan pascapersalinan ataupun tindakan obstetrik yang meningkat. Tujuan penelitian untuk mengetahui hubungan paritas dengan kejadian kehamilan postterm di RSUD Embung Fatimah Kota Batam 2013.

Penelitian ini merupakan penelitian studi analitik dengan menggunakan pendekatan case control, sampel yang diambil dari total populasi dengan teknik sampel jenuh. Jumlah sampel 23 orang dari 718 populasi.

Dari hasil perhitungan Chi-Square didapatkan nilai p-value sebesar 0.278. Hal ini menunjukkan bahwa hasil $p$-value $(0.278)>0.05$ sehingga dapat disimpulkan bahwa tidak ada hubungan yang signifikan antara paritas dengan kejadian kehamilan postterm.

Kesimpulan dari hasil penelitian ini adalah mayoritas ibu bersalin yang mengalami kehamilan postterm di RSUD Embung Fatimah adalah ibu dengan paritas primipara namun tidak ada hubungan yang signifikan antara paritas dengan kejadian kehamilan postterm. Sehingga disarankan kepada calon ibu untuk mencatat saat haid setiap bulan agar mengetahui secara dini hari pertama haid terakhir. Ibu hamil diharapkan rutin melakukan pemeriksaan kehamilan sehingga terhindar dari komplikasi yang tidak diharapkan.
\end{abstract}

Kata kunci : Paritas, kehamilan postterm

\section{ABSTRACT}

Cause of mortality and morbidity is one of postterm pregnancy. Because it influences the mother and the fetus. On fetal weight gain may occur continuously, there is no increase, there is a birth weight less than it should be, or died in the womb due to lack of nutrients and oxygen. Meanwhile, the mother may be a risk for postpartum hemorrhage or increased obstetric measures. Research purposes to determine the relationship of parity with the incidence of postterm pregnancy in Embung Fatimah Hospital Batam 2013.

This research is analytic studies using case control approach, samples are drawn from the total population of the totally sampling technique. Number of samples 23 from 718 population. 
From the calculation of Chi-Square p-value obtained for 0.278 this suggests that the results of $\mathrm{p}$ value $(0.278)>0.05$, so it can be concluded that there is no significant relationship between the incidence of postterm pregnancy parity.

The conclusion from this study is that the majority of women who experience pregnancy postterm birth in Embung Fatimah Hospital was primiparous mothers with parity, but there was no significant association between parity with the incidence of postterm pregnancy. So it is recommended to mothers to take notes during menstruation each month in order to find out early on the first day of last period. Pregnant women are expected to perform routine prenatal care so avoid unexpected complications.

Keywords: Parity, Postterm pregnancy 
Angka Kematian Ibu (AKI) dan Angka Kematian Bayi (AKB) merupakan indikator yang lazim digunakan dalam menentukan derajat kesehatan masyarakat, penilaian keberhasilan pelayanan kesehatan dan program pembangunan kesehatan baik provinsi maupun nasional (Syafei, 2010).

Sebanyak 37 juta kelahiran terjadi di kawasan Asia Tenggara setiap tahun, sementara total kematian ibu dan bayi baru lahir di kawasan ini diperkirakan berturutturut 170 ribu dan 1,3 juta per tahun. Sebanyak $98 \%$ dari seluruh kematian ibu dan anak di kawasan ini terjadi di India, Bangladesh, Indonesia, Nepal dan Myanmar (WHO, 2008).

Berdasarkan Survey Demografi Kesehatan Indonesia (SDKI) Tahun 2011 jumlah Angka Kematian Ibu (AKI) sebanyak 121/ $100.000 \mathrm{KH}$ telah terjadi penurunan pada Tahun 2012 sebanyak 118/ 100.000 KH dan Angka kematian Bayi (AKB) Tahun 2011 sebanyak 34/ $1000 \mathrm{KH}$ telah terjadi penurunan pada Tahun 2012 sebanyak 32/ 1000 KH. Namun belum dapat mencapai target Millennium Development Goals (MDGs) 2015 yaitu sebanyak 102/ 100.000 KH dan Angka Kematian Bayi (AKB) sebanyak 24/ 1000 KH (Kemenkes RI, 2013).

Jumlah Angka Kematian Ibu (AKI) di Kota Batam Tahun 2010 sebanyak $113,8 / 100.000 \mathrm{KH}$ terjadi penurunan pada Tahun 2011 sebanyak 78,6/ $100.000 \mathrm{KH}$ (Dinkes Kota Batam, 2012).

$$
\text { Jumlah Angka Kematian Bayi }
$$

(AKB) di Kota Batam Tahun 2009 sebanyak 7,1/ $1000 \mathrm{KH}$ lebih tinggi di bandingkan dengan Lingga sebanyak 4,5/1000 KH dan Anambas sebanyak 2,6/ $1000 \mathrm{KH}$ (Dinkes Provinsi Kepulauan Riau, 2009).

Jumlah AKB di Batam Tahun 2010 sebanyak 6.29/ $1000 \mathrm{KH}$ dan terjadi penurunan di Tahun 2011 sebanyak 4/ $1000 \mathrm{KH}$. Hal ini menunjukkan bahwa penurunan yang sangat signifikan berdasarkan target Millennium Development Goals (MDGs) Tahun 2015 yaitu sebanyak 24/ 1000 KH (Dinkes Kota Batam, 2012).

Penyebab mortalitas dan morbiditas salah satunya adalah kehamilan postterm. Karena sangat berpengaruh terhadap ibu dan janin yang dikandungnya. Pada janin dapat terjadi peningkatan berat badan secara terus menerus, ada yang tidak bertambah, ada yang lahir dengan berat badan kurang dari semestinya, atau meninggal dalam kandungan karena kekurangan zat makanan dan oksigen. Sementara itu, resiko bagi ibu dengan kehamilan postterm dapat berupa perdarahan pascapersalinan ataupun tindakan obstetrik yang meningkat (Prawirohardjo, 2008).

Faktor yang mempengaruhi terjadinya kehamilan postterm salah satunya adalah paritas. Beberapa teori menyatakan bahwa terjadinya kehamilan postterm adalah riwayat kelahiran sebelumnya, kelas sosial ekonomi dan umur, (Cunningham, 2006). Ada juga yang menyatakan bahwa terjadianya kehamilan postterm karena pengaruh perubahan hormon, siklus haid yang tidak teratur, genetik dan riwayat kehamilan sebelumnya, (Prawirohardjo, 2008).

Pencegahan yang dapat dilakukan agar tidak terjadi kehamilan postterm dengan cara melakukan pemeriksaan kehamilan dengan teratur, pemberian KIE (Konseling Informasi dan Edukasi) pada ibu tentang pentingnya pemeriksaan kehamilan secara teratur dan mengetahui HPHT (Hari Pertama Haid Terakhir) (Prawirohardjo, 2008).

Insiden rata-rata kehamilan lebih bulan adalah $10 \%$, tetapi menurun hingga $1,1 \%$ jika dilakukan penentuan usia kehamilan yang akurat. Berdasarkan data pada penelitian sebelumnya oleh Bakketeig dan Bengsjo Tahun 1989 menunjukan bahwa durasi kehamilan bervariasi sesuai paritas dan ras. Ibu primigravida memiliki durasi kehamilan yang lebih lama yaitu sekitar 288 hari. Ibu multigravida memiliki rata-rata 283 hari dan risiko terjadinya kembali kelahiran 
lebih bulan meningkat dengan sejalan dengan bertambahnya paritas (Fraser, 2009).

Berdasarkan hasil laporan Audit Maternal Perinatal (AMP) RSUD Embung Fatimah Kota Batam Tahun 2011 jumlah ibu bersalin dengan kehamilan postterm sebanyak 9 orang, sedangkan Tahun 2012 sebanyak 23 orang. Terjadi peningkatan yang sangat signifikan dan rata-rata adalah primigravida.

Oleh karena itu penulis merasa perlu untuk melakukan penelitian dengan judul "Hubungan antara Paritas dengan Kejadian Kehamilan Postterm di RSUD Embung Fatimah Tahun 2013".

\section{METODE}

Desain penelitian yang digunakan dalam penelitian ini adalah studi analitik yaitu menganalisa ada tidaknya hubungan antara paritas dengan kejadian persalinan postterm.

Jenis penelitian yang digunakan oleh peneliti adalah jenis penelitian yang bersifat kuantitatif yaitu data yang nilai variabelnya dapat diukur terus sampai sekecil-kecilnya. Penelitian ini menggunakan pendekatan case control yaitu suatu penelitian analitik yang menyangkut bagaimana faktor resiko dipelajari menggunakan pendekatan retrospective

Populasi dalam penelitian ini adalah seluruh ibu yang bersalin di Rumah Sakit Umum Daerah Embung Fatimah dari bulan Januari - Juni 2013 yaitu berjumlah 718 ibu bersalin.

Pengambilan sampel dalam penelitian ini dengan menggunakan teknik non-probability yaitu teknik pengambilan sampel dengan tidak memberikan peluang yang sama dari setiap anggota populasi, yang bertujuan tidak untuk generalisasi, yang berasas pada probabilitas yang tidak sama. Teknik pengambilan sampel dalam penelitian ini adalah sampling jenuh yaitu dengan cara mengambil semua anggota populasi menjadi sampel.
Sampel yang diambil adalah ibu bersalin yang mengalami kehamilan postterm di RSUD Embung Fatimah Januari - Juni 2013. Sampel yang diambil berjumlah 23 ibu dikarenakan data-data yang dibutuhkan tidak lengkap sehingga peneliti hanya mengambil sampel sebanyak 23 dari jumlah populasi sebanyak 718 .

Penelitian ini merupakan penelitian studi analitik dengan menggunakan pendekatan case control, sampel yang diambil dari total populasi dengan teknik sampel jenuh. Jumlah sampel 23 orang dari 718 populasi.

\section{HASIL}

Dari hasil penelitian tentang hubungan antara paritas dengan kejadian kehamilan postterm di RSUD Embung Fatimah Kota Batam selama Januari - Juni 2013 yang dilakukan pada tanggal $17 \mathrm{Juli}$ 2013.

1) Analisa univariat distribusi Frekuensi Kejadian Kehamilan Postterm Berdasarkan Faktor Paritas di RSUD Embung Fatimah Januari - Juni 2013

\begin{tabular}{|l|l|l|}
\hline Paritas & $\begin{array}{l}\text { Frekuensi } \\
\text { (f) }\end{array}$ & $\begin{array}{l}\text { Persentasi } \\
(\%)\end{array}$ \\
\hline Grandemultipara & 8 & 34.8 \\
\hline Multipara & 5 & 21.7 \\
\hline Primipara & 10 & 43.5 \\
\hline JUMLAH & 23 & 100 \\
\hline
\end{tabular}

2) Analisa univariat distribusi Frekuensi Kejadian Kehamilan Postterm di RSUD Embung Fatimah Januari Juni 2013

\begin{tabular}{|c|c|c|}
\hline $\begin{array}{c}\text { Kehamilan } \\
\text { Postterm }\end{array}$ & Frekuensi (f) & $\begin{array}{c}\text { Persentasi } \\
(\%)\end{array}$ \\
\hline Ya & 11 & 47.8 \\
\hline Tidak & 12 & 52.2 \\
\hline JUMLAH & 23 & 100 \\
\hline
\end{tabular}


3) Analisa bivariet distribusi Frekuensi Paritas dengan Kejadian Kehamilan Postterm di RSUD Embung Fatimah Kota Batam Januari - Juni 2013

\begin{tabular}{|c|c|c|c|c|c|c|c|}
\hline \multirow[t]{3}{*}{ Paritas } & \multicolumn{4}{|c|}{$\begin{array}{c}\text { Kejadian kehamilan } \\
\text { postterm }\end{array}$} & \multirow{2}{*}{\multicolumn{2}{|c|}{ Total }} & \multirow{2}{*}{$\begin{array}{l}\text { P- } \\
\text { val } \\
\text { ue }\end{array}$} \\
\hline & \multicolumn{2}{|c|}{ Tidak } & \multicolumn{2}{|c|}{$\mathrm{Ya}$} & & & \\
\hline & $\mathrm{f}$ & $\%$ & $\mathrm{~F}$ & $\%$ & $\mathrm{f}$ & $\%$ & 0.2 \\
\hline $\begin{array}{l}\text { Grande } \\
\text { multipar } \\
\text { a }\end{array}$ & 6 & 26.1 & 2 & 8.7 & 8 & $\begin{array}{c}34 . \\
8\end{array}$ & 78 \\
\hline $\begin{array}{l}\text { Multipar } \\
\text { a }\end{array}$ & 2 & 8.7 & 3 & 13 & 5 & $\begin{array}{c}21 . \\
7\end{array}$ & \\
\hline $\begin{array}{l}\text { Primipar } \\
\text { a }\end{array}$ & 4 & 17.4 & 6 & $\begin{array}{c}26 . \\
1\end{array}$ & $\begin{array}{l}1 \\
0\end{array}$ & $\begin{array}{c}43 . \\
5\end{array}$ & \\
\hline $\begin{array}{l}\text { JUMLA } \\
\mathrm{H}\end{array}$ & $\begin{array}{l}1 \\
2\end{array}$ & 52.2 & 11 & $\begin{array}{c}47 . \\
8\end{array}$ & $\begin{array}{l}2 \\
3\end{array}$ & $\begin{array}{c}10 \\
0\end{array}$ & \\
\hline
\end{tabular}

Dari hasil perhitungan Chi-Square didapatkan nilai p-value sebesar 0.278. hal ini menunjukkan bahwa hasil $\mathrm{p}$ value > $0.05(0.278>0.05)$ sehingga dapat disimpulkan bahwa tidak ada hubungan yang signifikan antara paritas dengan kejadian kehamilan postterm.

\section{PEMBAHASAN}

Berdasarkan analisa univariat distribusi Frekuensi Kejadian Kehamilan Postterm Berdasarkan Faktor Paritas di RSUD Embung Fatimah Januari - Juni 2013 dapat diketahui bahwa dari 23 ibu bersalin terdapat $10 \mathrm{ibu}(43.5 \%)$ dengan paritas primipara lebih banyak dibandingkan dengan ibu bersalin dengan paritas grandemultipara sebanyak 8 orang (34.8\%) dan multipara sebanyak $5 \mathrm{ibu}$ (21.7\%).

Berdasarkan analisa univariat distribusi Frekuensi Kejadian Kehamilan Postterm di RSUD Embung Fatimah Januari - Juni 2013 dapat diketahui bahwa dari $23 \mathrm{ibu}$ bersalin terdapat $11 \mathrm{ibu}$ $(47.8 \%)$ yang mengalami kehamilan postterm lebih sedikit dibandingkan dengan ibu yang tidak mengalami kehamilan postterm sebanyak 12 ibu $(52.2 \%)$.

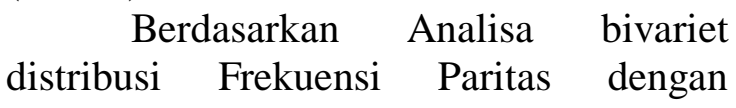

Kejadian Kehamilan Postterm di RSUD Embung Fatimah Kota Batam Januari Juni 2013 dapat diketahui bahwa ibu bersalin yang mengalami kehamilan postterm paling banyak terjadi pada ibu dengan paritas primipara yaitu sebanyak 6 orang $(26.1 \%)$ dibandingkan dengan paritas multipara 3 orang (13\%) dan grandemultipara 2 orang $(8.7 \%)$. Sedangkan ibu bersalin yang tidak mengalami kehamilan postterm paling banyak terjadi pada ibu dengan paritas grandemultipara yaitu sebanyak 6 orang (26.1\%) dibandingkan dengan paritas primipara 4 orang $(17.4 \%)$ dan multipara 2 orang $(8.7 \%)$.

Kejadian Kehamilan Postterm Berdasarkan Faktor ParitasBerdasarkan hasil penelitian yang telah dilakukan dapat diketahui bahwa dari 23 ibu bersalin terdapat $10 \mathrm{ibu}(43.5 \%)$ dengan paritas primipara lebih banyak dibandingkan dengan ibu bersalin dengan paritas grandemultipara sebanyak 8 orang $(34.8 \%)$ dan multipara sebanyak 5 orang $(21.7 \%)$.

Hal ini dikarenakan fungsi endometrium pada ibu primipara belum optimal sehingga menyebabkan serviks tidak matang dan tidak terjadi kontraksi sehingga terjadi kehamilan postterm. Oleh karena itu kehamilan postterm sangat rentan terjadi pada ibu dengan paritas primigravida.

Menurut Oxorn (2010), pada ibu hamil yang mengalami kehamilan postterm dengan paritas primipara harus segera dilakukan proses persalinan karena beresiko terjadi gawat janin. Gawat janin umumnya disebabkan oleh makrosomia yang dapat menyebabkan distosia pada persalinan, fraktur klavikula, sampai kematian bayi. Sedangkan pada ibu dapat terjadi partus lama, peningkatan tindakan obstetrik dan perdarahan postpartum. Kejadian Kehamilan Postterm berdasarkan hasil penelitian yang telah dilakukan dapat diketahui bahwa dari 23 ibu bersalin terdapat $11 \mathrm{ibu}(47.8 \%)$ yang mengalami kehamilan postterm lebih sedikit dibandingkan dengan ibu yang tidak 
mengalami kehamilan postterm sebanyak $12 \mathrm{ibu}(52.2 \%)$.

Hal ini dikarenakan ibu hamil melakukan kunjungan kehamilan secara rutin ke pelayanan kesehatan sehingga sebelum usia kehamilan ibu mencapai 42 minggu dan belum timbul tanda-tanda persalinan maka segera dilakukan tindakan pengakhiran kehamilan dengan memperhatikan kondisi ibu dan janin. Bila janin dalam keadaan baik maka dapat dilakukan induksi untuk merangsang timbulnya kontraksi atau bila janin dalam keadaan gawat dapat segera dilakukan operasi sectio caesarea. Mengakhiri kehamilan ini dilakukan untuk memperkecil resiko terhadap janin.

Menurut Chunnigham (2006), kehamilan postterm dipengaruhi oleh beberapa faktor yaitu umur, kelahiran postterm sebelumnya, kelahiran postterm sebelumnya dan kelas sosial ekonomi. Sedangkan menurut Sarwono (2008), kehamilan postterm dipengaruhi oleh hormon oksitosin, hormon progesteron, teori kortisol/ ACTH janin, saraf uterus dan herediter.

Hubungan antara paritas dengan kejadian kehamilan postterm berdasarkan hasil penelitian yang telah dilakukan dapat diketahui bahwa ibu bersalin yang mengalami kejadian kehamilan postterm paling banyak terjadi pada ibu bersalin dengan paritas primipara yaitu sebanyak 6 orang $(26.1 \%)$ dibandingkan dengan ibu bersalin dengan paritas multipara 3 ibu (13\%) dan grandemultipara $2 \mathrm{ibu}(8.7 \%)$. Sedangkan ibu bersalin yang tidak mengalami kejadian kehamilan postterm paling banyak terjadi pada ibu bersalin dengan paritas grandemultipara yaitu sebanyak 6 orang $(26.1 \%)$ dibandingkan ibu bersalin dengan paritas multipara $2 \mathrm{ibu}$ $(8.7 \%)$ dan primipara $4 \mathrm{ibu}(17.4 \%)$.

Dari hasil perhitungan Chi-Square didapatkan nilai $p$-value sebesar 0.278 . hal ini menunjukkan bahwa hasil $p$ value $(0.278)>0.05$ sehingga dapat disimpulkan bahwa tidak ada hubungan yang signifikan antara paritas dengan kejadian kehamilan postterm.

Hasil penelitian ini didukung oleh penelitian yang dikemukakan oleh Diana Handaria Tahun 2001 tentang "Faktorfaktor yang berhubungan dengan kejadian kehamilan lewat bulan" meyatakan tidak ada hubungan yang bermakna antara paritas dengan kehamilan postterm yaitu hasil $\mathrm{p}$ value $(0.977)>0.05$.

Penelitian ini tidak sesuai dengan teori yang dikemukaan oleh (Fraser, 2009) yang menyatakan ibu primigravida memiliki durasi kehamilan yang lebih lama yaitu sekitar 288 hari sedangkan ibu multigravida sekitar 283 hari dan beresiko terjadinya kembali kelahiran lebih bulan meningkat dengan sejalan bertambahnya paritas.

Pada usia kehamilan, 40 minggu, wanita mengalami stress tinggi yang mempengaruhi penurunan hormon prostaglandin sehingga menyebabkan serviks tidak matang dan tidak timbul kontraksi, menyebabkan kehamilan postterm. Kematangan serviks berhubungan dengan kesiapan jalan lahir setelah timbul tanda persalinan. Serviks multipara lebih cepat matang dibanding nullipara, dan pemahaman tentang paritas penting untuk menentukan saat yang tepat untuk melakukan pemeriksaan serviks kehamilan postterm (Varney, 2006).

Sedangkan menurut Chunningham (2006) faktor-faktor yang mempengaruhi kehamilan postterm tidak hanya dipengaruhi oleh paritas tetapi juga dipengaruhi oleh beberapa faktor yaitu, kelahiran postterm sebelumnya, kelas sosial ekonomi dan umur.

Hasil penelitian yang saya teliti tidak ada hubungan dikarenakan hanya menghubungkan satu faktor yaitu paritas dari beberapa faktor lain yang mempengaruhi terjadinya kehamilan postterm yaitu seperti umur, riwayat kelahiran postterm sebelumnya dan kelas sosial ekonomi sesuai dengan pendapat yang dikemukakan oleh (Cunningham, 2006). Selain itu menurut (Sarwono, 2008) 
menjelaskan bahwa yang mempengaruhi terjadinya kehamilan postterm yaitu pengaruh hormon oksitosin, hormon progesteron, teori kortisol/ ACTH janin, saraf uterus dan herediter.

Karena banyaknya faktor-faktor yang mempengaruhi terjadinya kehamilan postterm, sehingga paritas tidak berpengaruh besar terhadap kejadian kehamilan postterm di RSUD Embung Fatimah Batam.

Seiring perkembangan zaman, peningkatan ilmu pengetahuan dan teknologi saat ini membantu mempermudah tenaga kesehatan dalam upaya mencegah dan mengurangi terjadinya mortalitas dan morbiditas terhadap kehamilan sehingga dilakukan pemeriksaan kehamilan menggunakan Ultrasonografi (USG) dapat mengetahui usia kehamilan, jumlah cairan amnion dan pemeriksaan Non-Stress Test (NST) dapat mengetahui adakah gangguan kondisi janin serta pada saat ini tidak lagi menunggu hingga 42 minggu untuk melakukan induksi persalinan namun pada usia kehamilan 41 minggu sudah dilakukan induksi persalinan karena perlu pertimbangan mengenai reabilitas perkiraan tanggal kelahiran tidak dapat diandalkan sehingga perlu dilakukan intervensi agar kesejahteraan janin terjamin.

\section{SIMPULAN DAN SARAN Simpulan}

Berdasarkan hasil penelitian dan pengolahan data yang telah dilaksanakan oleh peneliti mengenai Hubungan antara Paritas dengan Kejadian Kehamilan Postterm di RSUD Embung Fatimah Kota Batam Tahun 2013 dengan 23 ibu bersalin, dapat disimpulkan bahwa:

a. Hasil penelitian menunjukkan bahwa dari 23 ibu bersalin di RSUD Embung Fatimah Tahun 2013 sebagian besar dengan paritas primipara.

b. Hasil penelitian menunjukkan bahwa dari 23 ibu bersalin di
RSUD Embung Fatimah Kota Batam Tahun 2013 sebagian besar tidak mengalami kehamilan postterm.

c. Tidak terdapat hubungan yang signifikan antara paritas dengan kejadian kehamilan postterm di RSUD Embung Fatimah Kota Batam Tahun 2013.

\section{Saran}

Disarankan dapat lebih meningkatkan pengetahuan tentang pentingnya pemeriksaan kehamilan secara rutin sehingga dapat mencegah terjadinya kehamilan postterm dan deteksi dini tanda bahaya dalam kehamilan.

DAFTAR PUSTAKA

Chandra, Dr.Budiman. 2008. Metodologi Penelitian Kesehatan. Jakarta ; EGC

Cunningham, F.Gary, dkk. 2006. Obstetri Williams vol. 1. Jakarta ; EGC

Diana Handaria, Faktor-faktor yang berhubungan dengan kejadian kehamilan lewat bulan di RS Dr. Kariadi, Semarang : 2001

Erawati,S.SiT, Ambar Dwi. 2011. Buku Ajar Asuhan Kebidanan Persalinan Normal. Jakarta ; EGC

Fraser, Diane. M \& Copper, Margaret. A. 2009. Myles Buku Ajar Bidan edisi 14. Jakarta ; EGC.

Hidayat, Aziz. 2010. Metodologi Penelitian Kebidanan dan Teknik Analisis Data. Jakarta ; Salemba Medika

Kesgakepri. 2010. Angka Kematian Bayi (AKB) 2009 dari sumber elektronik. http:www.kesgakepri.wordpress.com /2010/10/18/angka-kematian-bayiakb-2009/, diperoleh 20 Maret 2013.

Kesgakepri. 2010. Angka Kematian Ibu (AKI) dari sumber elektronik. 
http:www.kesgakepri.wordpress.com /2010/09/21/angka-kematian-ibuaki-2/, diperoleh 20 Maret 2013

Kriebs, Jan. M \& Gregor, Carolyn. L. 2009. Buku Saku asuhan kebidanan Varney Edisi 2. Jakarta ; EGC.

Lauren. A. Dutton dkk. 2012. Rujukan Cepat Kebidanan. Jakarta ; EGC

M.B.A, Dr. Riduwan. 2012. Dasar-Dasar Statistika. Bandung ; CV.Alfabeta

Manuaba, Ida Ayu Chandranita \& Manuaba, Ida Bagus Gde Fajar. 2008. Buku Ajar Patologi Obstetri untuk Mahasiswa Kebidanan. Jakarta ; EGC.

Newman Dorland, W.A. 2012. Kamus Saku Kedokteran DORLAND edisi 28, Jakarta ; EGC

Notoatmodjo, Prof Dr. Soekidjo. 2010. Metodologi Penelitian Kesehatan. Jakarta ; Rineka Cipta

Oxorn, Harry \& Forte, William.R. 2010. Ilmu Kebidanan : Patologi dan Fisiologi Persalinan, Yogyakarta ; CV.Offset

Prawirohardjo, Sarwono. 2008. Ilmu Kebidanan, Jakarta ; PT. Bina Pustaka Sarwono

Rahayu Sumaningsih, Hubungan antara paritas dengan kejadian kehamilan postterm di RSUD Harjono $S$, Ponorogo : 2010

Suharto, Agung. 2011. Jurnal Penelitian Kesehatan Suara Forikes Volume 2 nomor 2 dari sumber elektronik. http:/www.suaraforikes.webs.com, diperoleh 2 Juni 2013.

Varney, Helen. 2006. Buku Ajar Asuhan Kebidanan Volume 1 Edisi 4. Jakarta ; EGC.
Widodo, T. 2008. Metode Penelitian Kuantitatif. Surakarta ; LPP UNS dan UNS Press 